\title{
Stability of Trapped Electrons in $\mathrm{SiO}_{2}$
}

\author{
D. M. Fleetwood ${ }^{*}$ and P. S. Winokur \\ Sandia National Laboratories, Albuquerque, NM 87185-1083 USA \\ O. Flament and J. L. Leray \\ CEA/DRIF, BP 12, F-91680 Bruyères-Le-Châtel, FRANCE
}

\begin{abstract}
Thermally stimulated current and capacitance voltage methods are used to investigate the thermal stability of trapped electrons associated with radiation-induced trapped positive charge in metal-oxidesemiconductor capacitors. The density of deeply trapped electrons in radiation-hardened $45 \mathrm{~nm}$ oxides exceeds that of shallow electrons by a factor of $\sim 3$ after radiation exposure, and by up to a factor of 10 or more during biased annealing. Shallow electron traps anneal faster than deep traps, and seem to be at least qualitatively consistent with the model ofLelis et al. Deeper traps may be part of a fundamentally distinct dipole complex, and/or have shifted energy levels that inhibit charge exchange with the Si.
\end{abstract}

\footnotetext{
"Electronic Mail: dmfleet@sandia.gov
} 


\section{DISCLAIMER}

This report was prepared as an account of work sponsored by an agency of the United States Government. Neither the United States Government nor any agency thereof, nor any of their employees, make any warranty, express or implied, or assumes any legal liability or responsibility for the accuracy, completeness, or usefulness of any information, apparatus, product, or process disclosed, or represents that its use would not infringe privately owned rights. Reference herein to any specific commercial product, process, or service by trade name, trademark, manufacturer, or otherwise does not necessarily constitute or imply its endorsement, recommendation, or favoring by the United States Government or any agency thereof. The views and opinions of authors expressed herein do not necessarily state or reflect those of the United States Government or any agency thereof. 


\section{DISCLAIMER}

Portions of this document may be illegible in electronic image products. Images are produced from the best available original document. 
Electron trapping near the $\mathrm{Si} / \mathrm{SiO}_{2}$ interface can strongly affect the response of metal-oxidesemiconductor (MOS) devices to ionizing radiation or high-field stress. ${ }^{1-6}$ These electrons can be present at densities exceeding $10^{12} \mathrm{~cm}^{-2}$, given similar amounts of trapped positive charge. 4,5 The nature of electron traps in the near-interfacial $\mathrm{SiO}_{2}$ is unknown, although there is compelling evidence these defects are often intimately associated with trapped holes. $3-5,7,8$ This relation is depicted most directly in the model of Lelis et al., which suggests trapped electrons and holes occupy opposite sides of a "compensated" $\mathrm{E}_{\gamma}^{\prime}$ center in $\mathrm{SiO}_{2} \cdot 3,8$ Charge exchange between electron traps and the $\mathrm{Si}$ occurs over a wide range of time scales, depending on the trap energy and/or location relative to the $\mathrm{Si} / \mathrm{SiO}_{2}$ interface. $6,9,10$

Here we report a detailed study of the stability of trapped electrons in $\mathrm{SiO}_{2}$. Capacitors with $45-\mathrm{nm}$ oxides were irradiated with $10-\mathrm{keV} x$ rays at $\sim 20^{\circ} \mathrm{C}$ to $2.0 \mathrm{Mrad}\left(\mathrm{SiO}_{2}\right)$ at $1100 \mathrm{rad}\left(\mathrm{SiO}_{2}\right) / \mathrm{s}$ and $10 \mathrm{~V}$ bias. Effective densities of shallow electron traps $\Delta N_{e s}$ were estimated via high-frequency $(1 \mathrm{MHz}) \mathrm{ca}-$ pacitance-voltage $(\mathrm{C}-\mathrm{V})$ hysteresis measurements $5,11-13$ at a ramp rate of $\sim 0.5 \mathrm{~V} / \mathrm{s}$; all $\mathrm{C}-\mathrm{V}$ data were taken at room temperature. Effective densities of more deeply trapped electrons $\Delta N_{e d}$ were estimated from thermally stimulated current (TSC) and high-frequency $\mathrm{C}-\mathrm{V}$ measurements (swept from negativeto-positive bias to exclude the contribution of shallow trapped electrons ${ }^{13}$ ) via the expression: 4,10

$$
A q \Delta N_{e d}=\Delta Q_{p}-C_{o x} \Delta V_{m g}
$$

Here $\Delta Q_{p}=A q \Delta N_{p}$ is the trapped positive charge obtained by integrating the TSC after correcting for parasitic leakage, $-q$ is the electronic charge, $\Delta N_{p}$ is the trapped positive charge density, $C_{O x}$ is the oxide capacitance, $A$ is the area, and $\Delta V_{m g}$ is the midgap voltage shift.4,5 TSC measurements were performed at $-12 \mathrm{~V}$ during $\mathrm{a} \sim 0.11^{\circ} \mathrm{C} / \mathrm{s}$ ramp from $\sim 20^{\circ} \mathrm{C}$ to $350^{\circ} \mathrm{C} .14$ To investigate the stability of the trapped charge, devices were annealed in two different ways between irradiation and TSC measurement. Isochronal anneals were performed on some devices for $0.25 \mathrm{~h}$ at temperatures from $20^{\circ} \mathrm{C}$ to $200^{\circ} \mathrm{C} .13$ Other devices were isothermally annealed for times ranging from $0.25 \mathrm{~h}$ to $744 \mathrm{~h}$ at $115^{\circ} \mathrm{C}$. 
Figure 1 shows $\Delta N_{p}, \Delta N_{e d}$, and $\Delta N_{e s}$ for devices irradiated to $2 \mathrm{Mrad}\left(\mathrm{SiO}_{2}\right)$ and annealed at (a) $0 \mathrm{~V}$ or (b) $-10 \mathrm{~V}$ for $0.25 \mathrm{~h}$ at temperatures ranging from 50 to $200^{\circ} \mathrm{C}$ before TSC measurements were performed. Data at different temperatures are for different capacitors, as each TSC measurement removed all radiation-induced charge from the devices. 14 The points at $20^{\circ} \mathrm{C}$ are controls for which no anneals were performed. After irradiation, the density of trapped positive charge (triangles) was $2.5 \times 10^{12} \mathrm{~cm}^{-2}$, the density of deeply trapped electrons (circles) was $1.3 \times 10^{12} \mathrm{~cm}^{-2}$, and the density of shallow trapped electrons (squarès) was $0.4 \times 10^{12} \mathrm{~cm}^{-2}$. In Figs. 1(a) and 1(b), values of $\Delta N_{p}$ decrease with increasing anneal temperature as expected. 1,10 The density of shallow trapped electrons also decreases systematically with increasing temperature in each case. In contrast, in Fig. 1(a) the density of deeply trapped electrons increases by up to $13 \%$ for temperatures below $125^{\circ} \mathrm{C}$, and decreases at higher temperatures. Even for negative bias anneals in Fig. 1(b), which might be expected to electrostatically expel electrons from the oxide, there is essentially no change in $\Delta N_{e d}$ until the temperature exceeds $100^{\circ} \mathrm{C}$. The stability of the deeply trapped electrons during these negative bias anneals is significant and surprising.

Figure 2 investigates the stability of the trapped charge for (a) $0 \mathrm{~V}$ and (b) $-10 \mathrm{~V}$ isothermal annealing at $115^{\circ} \mathrm{C}$. Here the trapped positive charge (triangles) and the shallow trapped electron densities (squares) decrease with increasing anneal time at either bias. For the $0 \mathrm{~V}$ anneal in Fig. 2(a), the density of deeply trapped electrons (circles) increases for times less than $1.5 \mathrm{~h}$, and decreases for longer times. For the $-10 \mathrm{~V}$ anneal in Fig. 2(b), the value of $\Delta N_{e d}$ is unchanged for times up to $1.5 \mathrm{~h}$, and decreases for longer annealing times. Note that longer annealing times at negative bias more efficiently remove deeply trapped electrons than annealing at $0 \mathrm{~V}$ (or positive 10,13 ) bias. In Fig. 2(a), both $\Delta N_{p}$ and $\Delta N_{e d}$ are $\approx$ $0.7 \times 10^{12} \mathrm{~cm}^{-2}$ after a $744 \mathrm{~h}$ (31 day) anneal at $0 \mathrm{~V}$, but in Fig. 2 (b) $\Delta N_{p} \approx 0.5 \times 10^{12} \mathrm{~cm}^{-2}$ and $\Delta N_{e d} \approx$ $0.15 \times 10^{12} \mathrm{~cm}^{-2}$ after similar anneals at $-10 \mathrm{~V}$.

In Fig. 3 we compare the relative stability of shallow and deeply trapped electrons during (a)isochronal and (b) isothermal anneals. In each case, the data are normalized to postirradiation values. For the isochronal anneals in Fig. 3(a), the greatest stability is exhibited by deeply trapped electrons during $0 \mathrm{~V}$. 
anneal (solid squares), with the next greatest by the deeply trapped electrons during $-10 \mathrm{~V}$ anneal (open squares). The stability of the shallow electrons during $-10 \mathrm{~V}$ (open circles) or $0 \mathrm{~V}$ (solid circles) anneals is similar, and less than the deeply trapped electrons in either case. At $100^{\circ} \mathrm{C}$, for example, the values of $\Delta N_{e d}$ for $0 \mathrm{~V}$ and $-10 \mathrm{~V}$ anneals in Fig. 3(a) are essentially equal to postirradiation levels. On the other hand, values of $\Delta N_{e s}$ are $\sim 30 \%$ lower than postirradiation levels. The annealing response of the radiation induced defects in Fig. 3(a) may differ from that of the high-field-stress induced defects studied by Bhat and Saraswat, ${ }^{11}$ who observed no temperature dependence of $\mathrm{C}-\mathrm{V}$ hysteresis in their devices for measuring temperatures between $20^{\circ} \mathrm{C}$ and $200^{\circ} \mathrm{C}$. (Recall that all $\mathrm{C}-\mathrm{V}$ measurements are performed at room temperature here.) For the isothermal anneals in Fig. 3(b), the overall trends are similar to Fig. 3(a). The deeply trapped electrons at $0 \mathrm{~V}$ bias (solid squares) exhibit the greatest stability, and the shallow electrons at $0 \mathrm{~V}$ (solid circles) exhibit the least stability.

In previous studies the density of shallow trapped electrons estimated via $\mathrm{C}-\mathrm{V}$ hysteresis has been observed to (1) increase logarithmically with increasing voltage ramp time, 12 (2) be relatively independent of measuring temperature, 11 and (3) exhibit a similar time-dependent buildup for postirradiation room-temperature storage similar to that of $E_{\gamma}^{\prime}$ centers. 15 These behaviors are consistent with expectations derived from the model of Lelis and co-workers, based on the reversible tunnel exchange of electrons between the $\mathrm{Si}$ and a shallow electron trap site on the $\mathrm{Si}$ atom opposing the Si that holds the trapped hole. 3,16 Hence, it is reasonable that the shallow trapped electrons are associated with defects that are at least qualitatively similar in nature to those envisioned by Lelis et al. This presumes that only an $\mathrm{O}$ vacancy separates the trapped positive and negative charge, and that the trapped electron is a position and energy level that facilitates exchange with the $\mathrm{Si}$ on the time scale of the $\mathrm{C}-\mathrm{V}$ measurements.

The more deeply trapped electrons are present after irradiation at densities that exceed those of the shallower traps in this study by a factor of $\sim 3$ after irradiation, and by as much as a factor of 10 or more during annealing. Looking at Figs. 1 and 2, the stability of these deeply trapped electrons is comparable to that of the trapped positive charge. Indeed, for the $0 \mathrm{~V}$ anneals in Figs. 1(a) and 2(a), it appears that 
trapped positive and deeply trapped negative charge are removed at roughly the same rates at higher temperatures and/or longer annealing times. This suggests that a large percentage of the oxide-trap charge in these devices consists of dipole complexes that are highly stable at room temperature. Thus, the deeply trapped electrons appear to be associated with defect or impurity levels that do not communicate readily with either the Si or the trapped positive charge. An obvious candidate for an impurity related center that might serve as an electron trap is a hydrogen complex near the $\mathrm{Si} / \mathrm{SiO}_{2}$ interface. ${ }^{17-20}$ Whatever the microstructure of this center, during negative bias TSC measurements it releases charge that transports across the oxide. So the positive side of the dipole is either simply a trapped hole, or else it is a defect that releases mobile positive charge when the device is baked to high temperature at large negative bias. The negative charge associated with this center returns to the Si only when the positive charge is released.

Because a border trap is defined as a near-interfacial oxide trap that exchanges charge with the $\mathrm{Si}, 10$ it is clear that most compensating electrons in these devices are stably trapped electrons (at least at room temperature), and so do not lie in border traps. This contrasts with the shallow electron traps measured via C-V hysteresis, which have been identified as "slow" border traps in previous studies, 15,17 and with still faster border traps $7,9,10,12,17$ that can be mistaken for interface traps. This emphasizes the wide range of time constants with which electrons can be exchanged with defects in the near-interfacial $\mathrm{SiO}_{2}$ in the presence of trapped positive charge, and highlights the need to characterize the role of these defects in device performance and long-term reliability.

We thank L. C. Riewe for experimental assistance, and P. Paillet, J. Gasiot, R. D. Schrimpf, M. R. Shaneyfelt, J. R. Schwank, H. J. Hjalmarson, and A. H. Edwards for stimulating discussions. The portion of this work performed at Sandia National Laboratories was supported by the US Dept. of Energy (DOE). Sandia is operated for DOE by Sandia Corporation, a Lockheed Martin Company, under Contract No. DE-AC04-94AL85000. 


\section{References}

1. J. R. Schwank, P. S. Winokur, P. J. McWhorter, P. V. Dressendorfer, F. W. Sexton, and D. C. Turpin, IEEE Trans. Nucl. Sci. 31, 1427 (1984).

2. Y. Nissan-Cohen, J. Shappir, and D. Frohman-Bentchkowsky, J. Appl. Phys. 58, 2252 (1985).

3. A. J. Lelis, H. E. Boesch, Jr., T. R. Oldham, and F. B. McLean, IEEE Trans. Nucl. Sci. 35, 1186 (1988); IEEE Trans. Nucl. Sci. 36, 1808 (1989).

4. D. M. Fleetwood, S. L. Miller, R. A. Reber, Jr., P. J. McWhorter, P. S. Winokur, M. R. Shaneyfelt, and J. R. Schwank, IEEE Trans. Nucl. Sci. 39, 2192 (1992).

5. D. M. Fleetwood and N. S. Saks, J. Appl. Phys. 79, 1583 (1996).

6. A. Meinertzhagen, C. Petit, G. Yard, M. Jourdain, and G. Salace, J. Appl. Phys. 79, 2549 (1996).

7. D. J. DiMaria, D. A. Buchanan, J. H. Stathis, and R. E. Stahlbush, J. Appl. Phys. 77, 2032 (1995); Y. Roh, L. P. Trombetta, and D. J. DiMaria, J. Non-Crys. Sol. 187, 165 (1995).

8. J. F. Conley, Jr., P. M. Lenahan, A. J. Lelis, and T. R. Oldham, IEEE Trans. Nucl. Sci. 42, 1744 (1995).

9. M. J. Uren, S. Collins, and M. J. Kirton, Appl. Phys. Lett. 54, 1448 (1989); M. J. Kirton and M. J. Uren, Adv. Phys. 38, 367 (1989).

10. D. M. Fleetwood, P. S. Winokur, R. A. Reber, Jr., T. L. Meisenheimer, J. R. Schwank, M. R. Shaneyfelt, and L. C. Riewe, J. Appl. Phys. 73, 5058 (1993).

11. N. Bhat and K. C. Saraswat, J. Appl. Phys. 84, 2722 (1998).

12. D. M. Fleetwood, M. R. Shaneyfelt, W. L. Warren, J. R. Schwank, T. L. Meisenheimer, and P. S. Winokur, Microelectron. Reliab. 35, 403 (1995).

13. D. M. Fleetwood, P. S. Winokur, M. R. Shaneyfelt, L. C. Riewe, O. Flament, P. Paillet, and J. L. Leray, IEEE Trans. Nucl. Sci. 45, 2366 (1998). 
14. R. A. Reber, Jr. and D. M. Fleetwood, Rev. Sci. Instrum. 63, 5714 (1992); D. M. Fleetwood, R. A. Reber, Jr., and P. S. Winokur, IEEE Trans. Nucl. Sci. 38, 1066 (1991).

15. W. L. Warren, D. M. Fleetwood, M. R. Shaneyfelt, P. S. Winokur, and R. A. B. Devine, Phys. Rev. B 50, 14710 (1994); IEEE Trans. Nucl. Sci. 41, 1817 (1994).

16. T. R. Oldham, A. J. Lelis, and F. B. McLean, IEEE Trans. Nucl. Sci. 33, 1203 (1986); A. J. Lelis and T. R. Oldham, IEEE Trans. Nucl. Sci. 41, 1835 (19.94).

17. D. M. Fleetwood, IEEE Nucl. Sci. 43, 779 (1996).

18. J. M. M. de Nijs, K. G. Druijf, V. V. Afanase'ev, E. van der Drift, and P. Balk, Appl. Phys. Lett. 65, 2428 (1994).

19. B. Sagnes, J. M. Moragues, K. Yckache, R. Jerisian, J. Oualid, and D. Vuillaume, J. Appl. Phys. 80, 5469 (1996).

20. R. E. Stahlbush, E. Cartier, and D. A. Buchanan, Microelectronic Engineering 28, 15 (1995). 


\section{Figure Captions}

Figure 1. Trapped-positive-charge (triangles), deep trapped-electron (circles), and shallow-trapped electron (squares) densities following $0.25 \mathrm{~h}$ anneals at (a) $0 \mathrm{~V}$ and (b) $-10 \mathrm{~V}$ after radiation. exposure to $2 \mathrm{Mrad}\left(\mathrm{SiO}_{2}\right)$ at $10 \mathrm{~V}$ for $0.0053 \mathrm{~cm}^{2}$ capacitors with $45-\mathrm{nm}$ radiation-hardened oxides.

Figure 2. Trapped-positive-charge (triangles), deep trapped-electron (circles), and shallow-trapped electron (squares) densities as a function of anneal time at $115^{\circ} \mathrm{C}$ at (a) $0 \mathrm{~V}$ and (b) $-10 \mathrm{~V}$ following radiation exposure to $2 \mathrm{Mrad}\left(\mathrm{SiO}_{2}\right)$ at $10 \mathrm{~V}$ for $0.0053 \mathrm{~cm}^{2}$ capacitors with $45-\mathrm{nm}$ radiation-hardened oxides.

Figure 3. Densities of deep (squares) and shallow (circles) trapped electrons for $0 \mathrm{~V}$ (solid symbols) and $-10 \mathrm{~V}$ (open symbols) (a) $0.25 \mathrm{~h}$ isochronal or (b) $115^{\circ} \mathrm{C}$ isothermal anneals following radiation exposure to $2 \mathrm{Mrad}\left(\mathrm{SiO}_{2}\right)$ at $10 \mathrm{~V}$ for $0.0053 \mathrm{~cm}^{2}$ capacitors with $45-\mathrm{nm}$ radiationhardened oxides. 

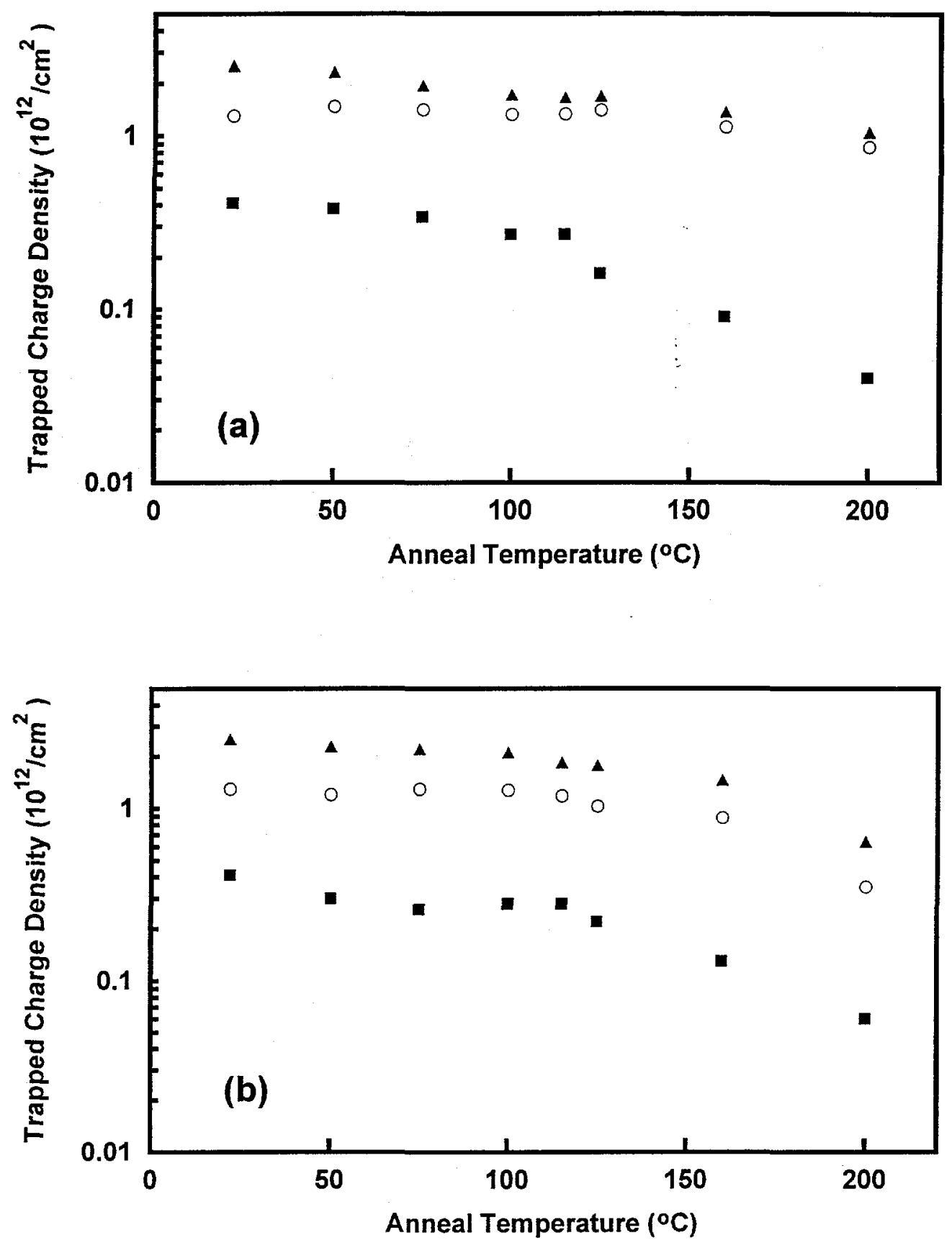

Fleetwood, APL Fig. 1 

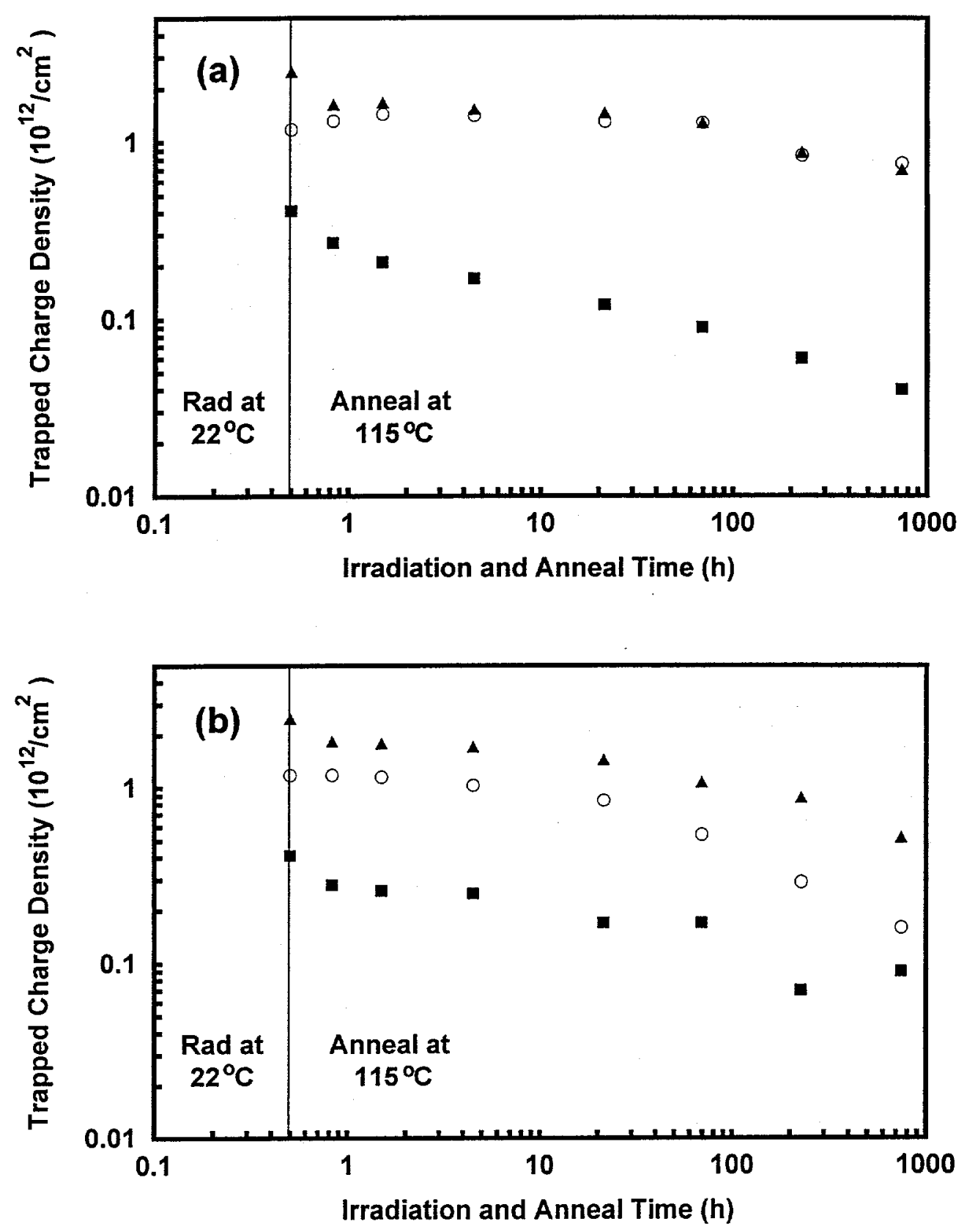

Fleetwood, APL. Fig. 2 

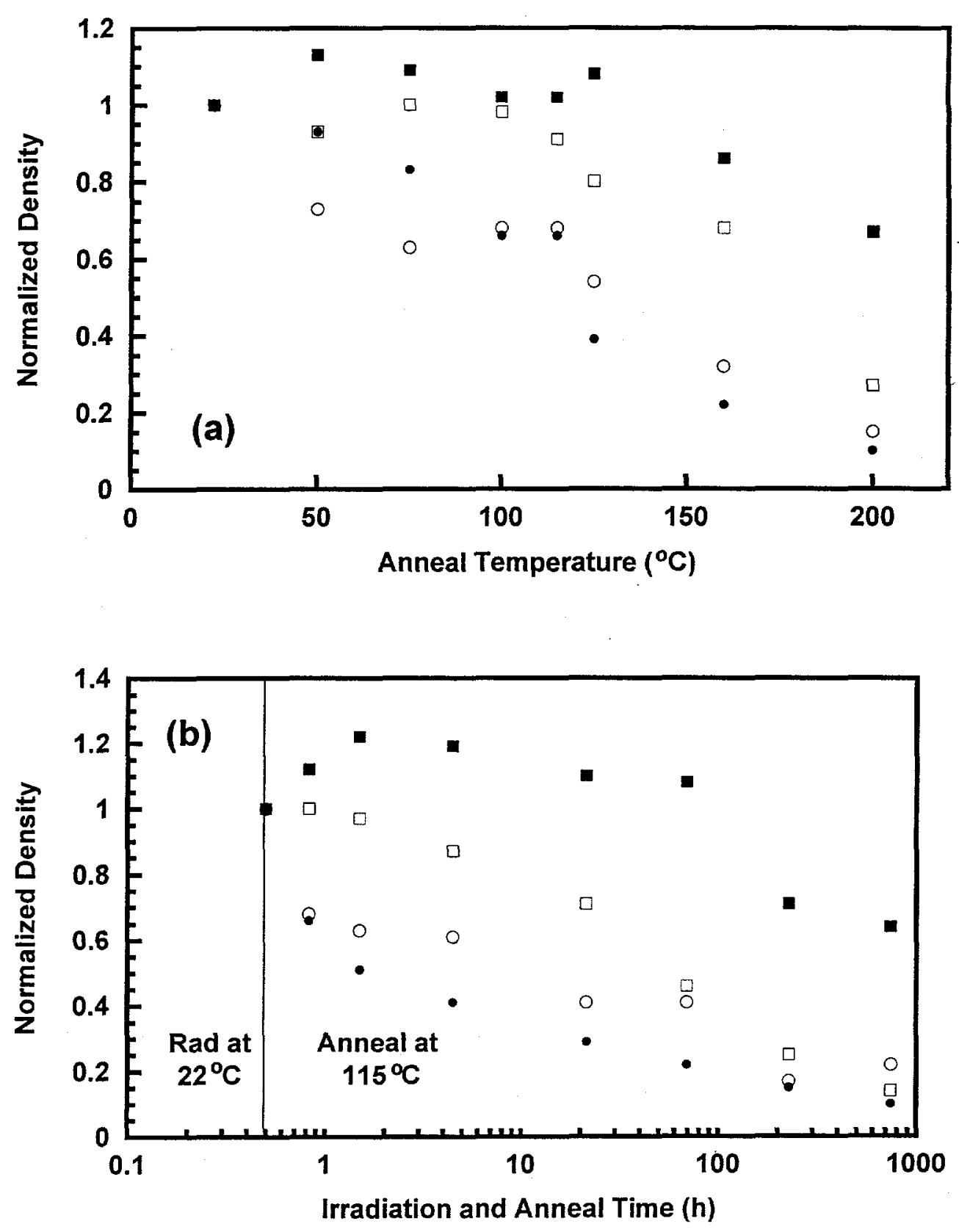

Fleetwood, APL, Fig. 3 